Jurnal Aplikasi Sains dan Teknologi - JAST, Volume 2, Nomor 1, Januari-Juni 2018, e-ISSN 2548-7981

\title{
PROGRAM PENGABDIAN MASYARAKAT MELALUI PENGOLAHAN BUAH KERSEN (Muntingia calabura L.)
}

\section{COMMUNITY SERVICE PROGRAM THROUGH PROCESSING FRUITS OF Muntingia calabura L.}

\author{
Jamilatur Rohmah ${ }^{*}$, Nurul Azizah ${ }^{2}$ \\ 1D-IV Teknologi Laboratorium Medis, Fakultas Ilmu Kesehatan, Universitas Muhammadiyah Sidoarjo. \\ ${ }^{2}$ D-III Kebidanan, Fakultas Ilmu Kesehatan, Universitas Muhammadiyah Sidoarjo. \\ 1.jamilaturrohmah@umsida.ac.id
}

\begin{abstract}
ABSTRAK
Desa Keboharan merupakan desa yang masuk pada wilayah kecamatan Krian kabupaten Sidoarjo. Sebagian besar masyarakat desa Keboharan adalah petani sawah dan buruh pabrik. Masyarakatnya memiliki potensi yang bisa dikembangkan, antara lain bidang pertanian dan industri rumah tangga, di bidang sosial memiliki PKK (Pembinaan Kesejahteraan Keluarga). PKK dusun Boharan dan Patoman merupakan salah satu wadah organisasi perempuan di desa Keboharan, Kecamatan Krian, Kabupaten Sidoarjo. Ibu-ibu PKK desa Keboharan memiliki latar belakang pendidikan yang beragam tetapi rata-rata hanya lulusan SMP dan SMA, dengan keadaan ekonomi keluarga yang berada pada ekonomi menengah ke bawah yang sebagian besar diantaranya adalah sebagai ibu rumah tangga. Hasil analisis menunjukkan belum optimalnya kegiatan PKK, yang disebabkan karena keterbatasan kemampuan dan keilmuan ibu-ibu PKK. Oleh karena itu diperlukan suatu solusi yang konkret sebagai upaya untuk meningkatkan keberdayaan ibu-ibu PKK tersebut melalui Program Pengabdian Masyarakat (PPM) berupa pelatihan pembuatan sabun dan detergen yakni sabun dan detergen cair herbal antibakteri ekstrak buah kersen (Muntingia calabura L.) beserta cara pengemasan produk dan pemasarannya. Pemilihan alternatif ini didasarkan pada kebutuhan akan keterampilan dan pengetahuan, yang dapat dijadikan bekal ibu-ibu PKK di desa Keboharan untuk merintis usaha serta latihan keterampilan. Selain itu di desa Keboharan banyak tumbuh tanaman kersen. Sehingga dengan adanya kegiatan ini diharapkan ibu-ibu PKK dapat melengkapi wawasan pengetahuan dan keterampilannya dalam berbagai segi kehidupan keluarga yang dapat digunakan sebagai bekal untuk membuka usaha keluarga yang pada akhirnya dapat menambah pemasukan keluarga dan menunjukkan eksistensi dirinya.
\end{abstract}

Kata-kata kunci: buah kersen (Muntingia calabura L.), PPM, pemberdayaan.

\section{ABSTRACT}

Keboharan village is a village that enters the district of Krian Sidoarjo. Most of Keboharan villagers are farmers and factory workers. The villagers have a potential that can be developed, such as agriculture and home industries, in the social field has PKK (Pembinaan Kesejahteraan Keluarga). PKK in Boharan and Patoman hamlet is one of the organization of women in Keboharan village, Krian sub-district, Sidoarjo district, East Java Province. PKK woman in Keboharan village has diverse educational background but

\footnotetext{
${ }^{1}$ * Corresponding author.

e-mail: jamilaturrohmah@umsida.ac.id
} 
on average only junior and senior high school graduates, with the state of the family economy in the middle to lower economy, most of whom are as housewives. The analysis shows that the PKK activity is not optimal, due to the limited ability and knowledge of PKK woman. Therefore we need a concrete solution as an effort to improve the empowerment of PKK woman through Community Service Program (PPM) in the form of training of soap and liquid detergent antibacterial herb extract Muntingia calabura $L$. along with the way of packaging products and marketing. The selection of these alternatives is based on the need for skills and knowledge that PKK woman in Keboharan village can be used to pioneer the business and practice these skills. In addition Keboharan village grows many Muntingia calabura L. plants. So with the existence of this activity is expected to PKK woman can complement the knowledge and skills in various aspects of family life that can be used to participate to meet the needs of his family so that can eventually increase family income and also to show his existence.

Keywords: kersen (Muntingia calabura L.), PPM, empowerment.

\section{PENDAHULUAN}

Desa Keboharan merupakan desa yang masuk pada wilayah kecamatan Krian kabupaten Sidoarjo. Sebagian besar masyarakat desa Keboharan adalah petani sawah dan buruh pabrik. Seperti halnya beberapa wilayah di kabupaten Sidoarjo yang memiliki potensi masyarakatnya di kecamatan Krian juga banyak yang memiliki potensi yang bisa dikembangkan, antara lain bidang pertanian dan industri rumah tangga, di bidang sosial memiliki PKK (Pembinaan Kesejahteraan Keluarga). Penggerak PKK diketuai oleh istri Pimpinan Daerah dalam hal ini yaitu Kepala Desa/Lurah, secara fungsional. Adanya peran yang nyata yang diwujudkan oleh istri Pimpinan Daerah dalam hal ini yaitu istri Kepala Desa/ Lurah beserta warga (ibu-ibu) merupakan kunci berkembangnya program dan kegiatan PKK. Memiliki paradigma baru, PKK merupakan organisasi sosial yang dapat menunjang peningkatan kualitas sumber daya manusia dalam masyarakat luas, hingga ke pelosok pedesaan di bumi nusantara ini, termasuk di Kabupaten Sidoarjo.

PKK ini merupakan suatu program yang memiliki tujuan memberdayakan keluarga untuk meningkatkan kesejahteraan dengan sasarannya adalah keluarga dan perempuan, karena perbaikan posisi dari kondisi perempuan yang masih di harapkan mampu memperbaiki atau membantu masalah-masalah yang ada baik dalam segi pendidikan, kesehatan atau perekonomian. Sehingga salah satu indikator meningkatnya kesejahteraan adalah keberdayaan perempuan di bidang ekonomi.

Salah satu wadah organisasi perempuan di desa Keboharan Kecamatan Krian Kabupaten Sidoarjo Provinsi Jawa Timur adalah PKK dusun Boharan dan Patoman. Jumlah anggota ibu-ibu PKK pada dusun Pesantren (mitra 1) adalah 20 orang. Keterlibatan para ibu dalam kegiatan PKK ini didasarkan pada keinginan untuk berorganisasi, bersilaturrahmi, sharing informasi, dll. yang tujuannya untuk dapat mensejahterakan keluarga. Ibu-ibu PKK di desa tersebut 
memiliki latar belakang pendidikan yang beragam tetapi rata-rata hanya lulusan SMP dan SMA, dengan keadaan ekonomi keluarga yang berada pada ekonomi menengah ke bawah yang sebagian besar diantaranya adalah sebagai ibu rumah tangga. Adanya pemenuhan kebutuhan sehari-hari yang perlu dicukupi mengharuskan pengeluaran yang terus meningkat, sedangkan semakin sulit untuk ibu-ibu ini mencari pekerjaan. Walaupun demikian, diyakini kaum ibu-ibu tersebut memiliki banyak kemampuan untuk meningkatkan kesejahteraan keluarga salah satunya melalui kegiatan PKK yang diikuti.

Kegiatan PKK yang dilakukan oleh ibu-ibu PKK di dusun Boharan yaitu arisan dan senam lansia yang pelaksanaannya dilakukan satu kali dalam satu bulan. Kegiatan arisan ini merupakan salah satu kegiatan yang bermanfaat, tidak hanya dalam bidang ekonomi dimana anggota juga dapat memanfaatkan simpan pinjam yang terdapat dalam PKK untuk membantu ekonomi rumah tangga masyarakat. Tetapi juga bermanfaat dalam bidang sosial, dimana dengan adanya arisan maka warga dapat turut berpartisipasi sebagai pengurus arisan ataupun berpartisipasi sebagai anggota arisan. Selain itu ada rasa timbal balik antar sesama warga yang terlihat saat ada warga yang sedang mengalami kesulitan, atau ada warga yang sedang membuat acara yang terlihat dari tindakan proaktif yang dilakukan warga.

Demikian halnya dengan ibu-ibu PKK di dusun Patoman (mitra 2) desa Keboharan Kecamatan Krian Kabupaten Sidoarjo Provinsi Jawa Timur. Ibu-ibu PKK di dusun ini memiliki anggota berjumlah 15 orang dengan latar belakang pendidikan yang juga beragam (lulusan SMP dan SMA) dengan kondisi ekonomi yang menengah ke bawah dan rata-rata sebagai ibu rumah tangga. Dengan latar belakang tersebut, tidak menyurutkan ibuibu ini untuk terlibat dalam kegiatan PKK dimana dengan mengikuti kegiatan PKK mereka dapat bersilaturrahmi, berorganisasi, berinteraksi, berbagi informasi, dll. yang tujuannya agar dapat meningkatkan kesejahteraan keluarga yang disebabkan karena adanya pemenuhan kebutuhan sehari-hari yang mengharuskan pengeluaran yang terus meningkat, sedangkan untuk ibu-ibu ini sudah semakin sulit mencari pekerjaan. Seperti halnya dengan kegiatan ibu-ibu PKK dusun Patoman, kegiatan ibu-ibu PKK di dusun Patoman adalah juga arisan dan senam lansia dimana kegiatan tersebut bermanfaat secara ekonomi dan sosial.

Namun kegiatan ibu-ibu PKK di kedua dusun tersebut belum berjalan optimal. Hasil analisis menunjukkan belum optimalnya kegiatan PKK, karena keterbatasan pengetahuan dan keterampilan ibu-ibu PKK. Karena kegiatan ibuibu PKK hanya terbatas pada penyelenggaraan kegiatan bulanan seperti arisan dan senam lansia. Selain itu juga minimnya sarana dan prasarana yang dimiliki oleh ibu-ibu PKK tersebut.

Oleh karena itu diperlukan upayaupaya lain untuk meningkatkan pengetahuan dan keterampilan ibu-ibu PKK tersebut, yang bertujuan untuk meningkatkan pendapatan keluarga dalam usaha mencapai keluarga yang bahagia dan sejahtera dengan cara menumbuhkan kemandirian dan kesadaran dalam berusaha, yang sekaligus dapat memperluas lapangan kerja serta untuk meningkatkan kemampuan dan keilmuan 
ibu-ibu PKK sebagai bekal merintis usaha. Hal ini sangat penting dilakukan yang didasarkan pada ibu-ibu PKK sebagai anggota masyarakat yang masih tergolong sebagai tenaga kerja yang produktif.

Berbagai alternatif kegiatan dapat dilakukan dalam upaya untuk membina dan mengembangkan potensi keluarga dan desa, salah satunya dapat berupa kegiatan pelatihan pembuatan sabun dan detergen yakni sabun dan detergen cair herbal antibakteri ekstrak buah kersen (Muntingia calabura L.) beserta cara pengemasan produk dan pemasarannya. Salah satu komoditas sehari-hari yang tidak bisa dilepaskan dari kebutuhan rumah tangga dewasa ini adalah sabun dan detergen. Dimana dalam proses pembuatannya alat produksi yang digunakan tidaklah rumit dan banyak. Pemilihan alternatif ini didasarkan pada kebutuhan akan keterampilan dan pengetahuan yang oleh ibu-ibu PKK di desa Keboharan dapat dijadikan bekal untuk merintis usaha serta latihan keterampilan ini mereka belum pernah mendapatkan dan proses pembuatan sabun dan detergen cair lebih mudah dibandingkan dengan sabun padat dan detergen bubuk [4].

Selain itu di desa Keboharan banyak tumbuh tanaman kersen (Muntingia calabura L.) dimana tanaman ini tidak terawat dan hanya dimanfaatkan sebagai peneduh. Bahkan buah kersen ini dianggap bila dimakan dapat menyebabkan penyakit typhoid. Hal ini disebabkan karena mereka belum mengetahui kandungan dalam tanaman ini. Padahal tanaman kersen mengandung berbagai manfaat penting dan baik untuk kesehatan. Salah satunya yaitu manfaat sebagai antiseptik (antibakteri) [1]. Ibu-ibu akan lebih mudah menyesuaikan dengan perannya sebagai ibu rumah tangga karena kegiatan yang ditawarkan ini dapat dikerjakan di rumah.

Melalui kegiatan ini diharapkan ibu-ibu PKK dapat melengkapi wawasan pengetahuan dan keterampilannya dalam berbagai segi kehidupan keluarga yang dapat digunakan untuk ikut memenuhi kebutuhan keluarganya sehingga akan dapat menghemat keuangan keluarga karena dapat melakukan sendiri serta sebagai bekal untuk membuka usaha keluarga yang pada akhirnya dapat menambah pemasukan keluarga. Selain itu dapat juga untuk menunjukkan eksistensi dirinya.

\section{METODE KEGIATAN}

Dalam pelaksanaan PPM-TKP Ibu-ibu PKK Desa Keboharan Kecamatan Krian Kabupaten Sidoarjo Provinsi Jawa Timur metode pelaksanaannya adalah sebagai berikut:

\section{Persiapan Pelatihan}

Sebelum kegiatan seminar dan pelatihan pembuatan sabun \& detergen herbal antibakteri di lakukan pada Ibu-ibu PKK dusun Boharan dan Patoman, terlebih dahulu tim pengusul mempersiapkan materi seminar, bahan-bahan untuk pelatihan pembuatan sabun dan detergen cair herbal antibakteri. Kegiatan seminar dan pelatihan dilaksanakan di balai desa bersama mitra, dan bekerjasama dengan kepala desa dan perangkat desa Keboharan. Rencana kegiatan implementtasi tersebut mencakup:

a. Mempersiapkan materi atau powerpoint untuk seminar ke mitra.

b. Mempersiapkan modul pelatihan yang meliputi bahan pembuatan sabun dan detergen cair herbal antibakteri, 
manual book (buku petunjuk) cara pembuatan sabun dan detergen cair herbal antibakteri herbal, desain kemasan sabun dan detergen, dan metode pemasaran.

c. Pembagaian tugas tim pengusul untuk diskusi dan melayani pertanyaan dari peserta.

d. Mempersiapkan kuisioner sebagai umpan balik dari pelatihan.

\section{Pelaksanaan Seminar}

Sebelum dilakukan pelatihan pembuatan sabun dan detergen cair herbal antibakteri dari buah tanaman kersen, masyarakat desa Keboharan melalui mitra Ibu-ibu PKK dusun Boharan dan Patoman diperkenalkan dulu tentang tanaman kersen atau talok yang meliputi kandungan apa saja yang terdapat pada tanaman kersen dan dapat difungsikan sebagai apa saja pada tanaman kersen, serta seberapa banyak tanaman kersen berada di desa Keboharan. Informasi semua ini bisa diketahui melalui seminar yang dilaksanakan oleh tim PPM-TKP dari UMSIDA (Universitas Muhammadiyah Sidoarjo).

\section{Pelaksanaan Pelatihan Pembuatan} Sabun dan detergen

Pelatihan pembuatan sabun dan detergen herbal antibakteri dilakukan di balai desa dengan mitra Ibu-ibu PKK dusun Boharan dan Patoman yang meliputi:

a. Dimana para mitra terlebih dahulu diperkenalkan bahan-bahan apa saja yang mendukung untuk pembuatan sabun dan detergen herbal antibakteri.

b. Menunjukkan peralatan-peralatan yang dipakai untuk proses pembuatan sabun dan detergen herbal antibakteri dan memiliki fungsi apa saja. c. Menunjukkan ukuran atau takaran bahan yang sesuai untuk menjadi satu pruduk sabun dan detergen cair herbal antibakteri. Sehingga untuk membuat sejumlah produk sabun dan detergen cair nantinya tinggal mengalikan bahannya dengan satu produk sabun dan detergen tersebut.

d. Melatih bagaimana cara membuat sabun dan detergen cair herbal antibakteri dari buah tanaman kersen secara tepat dan benar.

\section{Pelaksanakan Pelatihan Desain Kemasan Sabun dan Detergen}

Setelah pembuatan sabun dan detergen cair herbal antibakteri selesai sehingga menghasilkan beberapa sabun dan detergen yang belum dikemas dengan baik maka dilakukan pelatihan desain kemasan sabun dan detergen cair sehingga nantinya memiliki nilai jual tinggi. Langkah-langkahnya meliputi :

a. Memberikan contoh-contoh kemasaan sabun dan detergen dari produk lain, agar para mitra memiliki imajinasi untuk memunculkan ide bentuk kemasan yang bagus untuk sabun dan detergen cair herbal antibakteri tersebut.

b. Melatih pembuatan desain kemasan sabun dan detergen herbal antibakteri tersebut, sehingga memiliki nilai jual yang tinggi kedepannya.

\section{Pelaksanakan Pelatihan Pemasaran}

Dimana media sosial, atau pemasaran secara online medianya sudah dibuatkan oleh Tim PPM-TKP. Tim memberikan pelatihan penggunaannya serta bagaimana cara update data ke dalam media. 


\section{KARYA UTAMA}

Hasil dari kegiatan program pengabdian masyarakat (PPM) melalui pengolahan buah kersen (Muntingia calabura L.) pada ibu-ibu PKK dusun Boharan dan Patoman desa Keboharan Kecamatan Krian Kabupaten Sidoarjo untuk memproduksi sabun dan detergen cair herbal antibakteri yaitu:

1. Terbentuknya Usaha Sabun dan Detergen Herbal Antibakteri Ekstrak Buah Kersen (Muntingia calabura L.)

Terbentuknya usaha sabun dan detergen herbal antibakteri ekstrak buah kersen (Muntingia calabura L.) ini berasal dari proses diskusi antara tim PPM dengan ibu-ibu PKK dari kedua dusun dengan memperhatikan potensi desa yang banyak tumbuh tanaman kersen (Muntingia calabura L.) yang kurang termanfaatkan serta belum pernahnya ibu-ibu PKK ini memperoleh pelatihan yang sejenis dan kurangnya pengetahuan tentang manfaat tanaman kersen, maka usaha sabun dan detergen herbal antibakteri ekstrak buah kersen (Muntingia calabura L.) dipilih untuk memulai usaha. Usaha sabun dan detergen herbal antibakteri ekstrak buah kersen (Muntingia calabura L.) kering disepakati oleh ibu-ibu PKK dari kedua dusun karena dapat melengkapi wawasan pengetahuan dan keterampilannya dalam berbagai segi kehidupan keluarga yang dapat digunakan untuk ikut memenuhi kebutuhan keluarganya sehingga akan dapat menghemat keuangan keluarga karena dapat melakukan sendiri.

2. Produksi Sabun dan Detergen Cair Herbal Antibakteri Ekstrak Buah Kersen (Muntingia calabura L.)
Produk berupa sabun mandi cair, sabun cuci tangan cair, dan deterjen cair. Modul produksi sabun dan detergen berisi tentang tanaman kersen dan khasiatnya, bahan-bahan, alat-alat dan cara pembuatan sabun mandi cair, sabun cuci tangan cair, dan deterjen cair. Tim PPM pada tahap persiapan pelatihan, melakukan uji coba formula pembuatan produk sabun dan deterjen cair [2], sehingga didapatkan komposisi yang tepat, dan memberikan hasil optimal (produk contoh). Formula sabun dan detergen cair herbal antibakteri ekstrak buah kersen adalah sebagai berikut:

a. Sabun mandi cair herbal antibakteri ekstrak buah kersen, dengan komposisi:

1) Minyak $\rightarrow 75 \mathrm{~mL}$

2) $\mathrm{KOH}$ (Kalium Hidroksida) $\rightarrow 25$ gram

3) CMC (Carboxy Methil Cellulose) $\rightarrow$ 2,5 gram

4) Texapon $\rightarrow 2,5$ gram

5) Asam Stearat $\rightarrow$ 1,25 gram

6) STPP (Sodium Tri Poli Phosphat) $\rightarrow$ 2,5 gram

7) Pewangi $\rightarrow 5 \mathrm{~mL}$

8) Pewarna $\rightarrow 1$ gram

9) Ekstrak buah kersen $\rightarrow 2 \mathrm{~mL}$

b. Sabun cuci tangan herbal antibakteri ekstrak buah kersen, dengan komposisi:

1) Texapon $\rightarrow 150$ gram

2) Comperland $\rightarrow 20 \mathrm{~mL}$

3) $\mathrm{NaCl} \rightarrow 25$ gram

4) Pewangi $\rightarrow 5 \mathrm{~mL}$

5) Pewarna $\rightarrow 1$ gram

6) Air $\rightarrow 900 \mathrm{~mL}$

7) Ekstrak buah kersen $\rightarrow 2 \mathrm{~mL}$

c. Detergen cair herbal antibakteri ekstrak buah kersen, dengan komposisi: 
1) Texapon $\rightarrow 40$ gram

2) Soda Abu $\rightarrow 80$ gram

3) Air $\rightarrow 850 \mathrm{~mL}$

4) Pewangi $\rightarrow 5 \mathrm{~mL}$

5) Pewarna $\rightarrow 1$ gram

6) Ekstrak buah kersen $\rightarrow 2 \mathrm{~mL}$

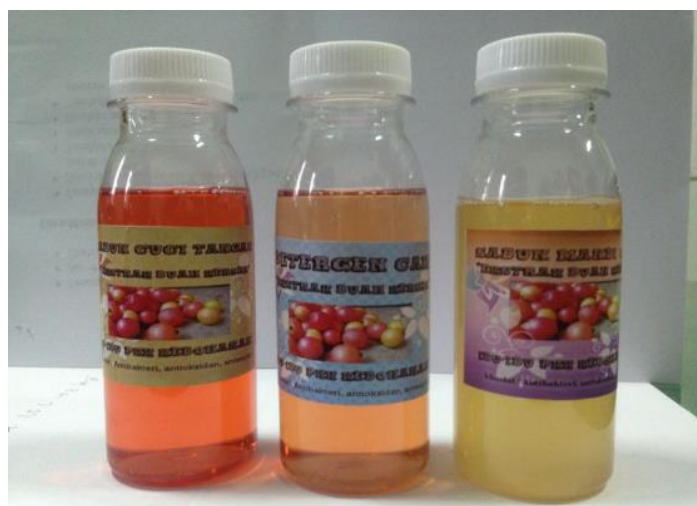

Gambar 1. Produk contoh sabun mandi, sabun cuci tangan, dan detergen cair herbal antibakteri ekstrak buah kersen.

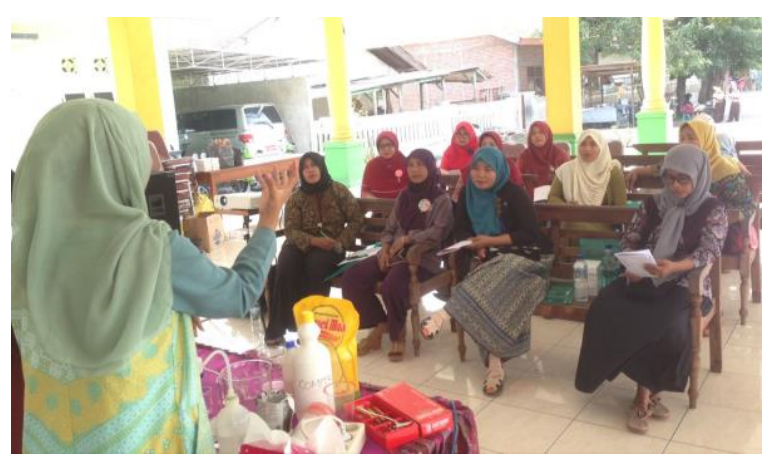

Gambar 2. Pelatihan pembuatan sabun mandi, sabun cuci tangan, dan detergen cair herbal antibakteri ekstrak buah kersen.

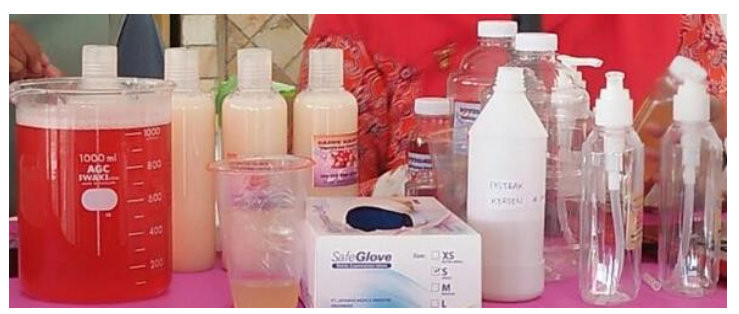

Gambar 3. Hasil produk sabun dan detergen cair
3. Pembuatan Desain Kemasan Produk Sabun dan Detergen Cair Herbal Antibakteri Ekstrak Buah Kersen (Muntingia calabura L.)

Pembuatan desain kemasan sabun dan detergen cair dilakukan dengan: 1) memberikan contoh-contoh kemasan sabun dan detergen cair dari produk lain, agar para mitra memiliki imajinasi untuk memunculkan ide bentuk kemasan yang bagus untuk sabun dan detergen cair herbal tersebut, dan 2) melatih pembuatan desain kemasan sabun dan detergen cair herbal tersebut, sehingga memiliki nilai jual yang tinggi kedepannya.

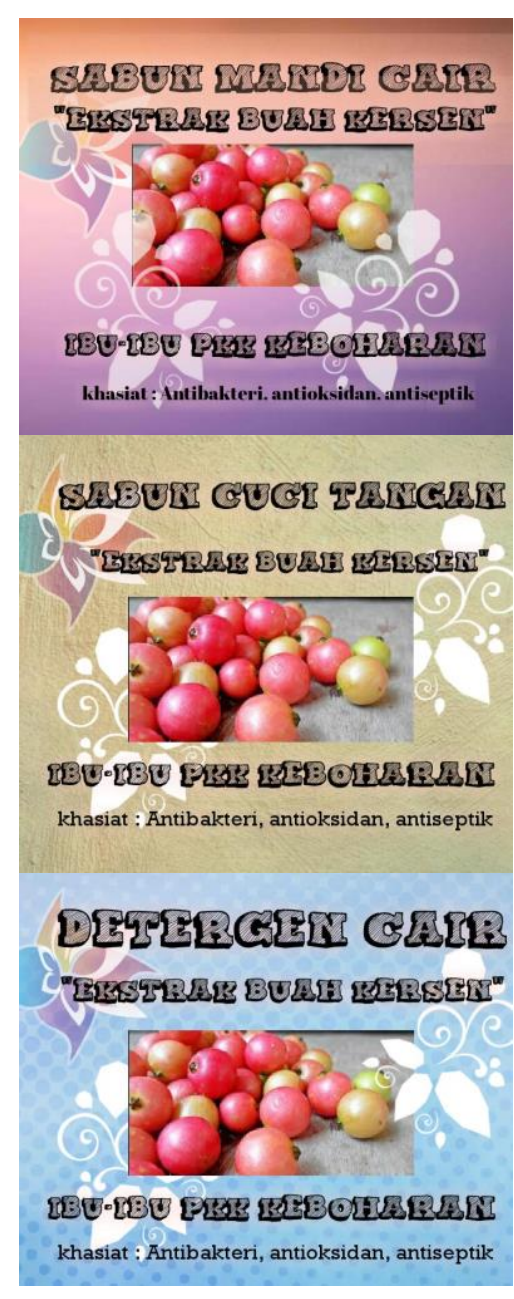

Gambar 4. Hasil desain label kemasan sabun dan detergen cair. 
4. Pemasaran Produk Sabun dan Detergen Cair Herbal Antibakteri Ekstrak Buah Kersen (Muntingia calabura L.)

Pemasaran produk dilakukan melalui media sosial, atau pemasaran secara online medianya sudah dibuatkan oleh Tim PPM. Tim memberikan pelatihan penggunaannya serta bagaimana cara update data ke dalam media. ičpipemasaran online dengan media sosial sebagai media pemasaran yang dapat memasarkan produk sabun dan detergen cair herbal antibakteri ekstrak buah kersen dengan lebih luas [3,5]. Sehingga dapat mewujudkan kemandirian masyarakat pedesaan khususnya desa Keboharan agar mampu mendayagunakan mengoptimalkan potensi sumberdaya lingkungan untuk kesejahteraan masyarakat.

\section{Pembuatan Pembukuan Sederhana \\ Pembukuan sederhana ini merupa-} kan suatu upaya untuk mencatat dan mengontrol pengeluaran dan pemasukan serta pembagian hasil para anggota usaha sesuai dengan pembagian kerja. Pembukuan sederhana dilakukan dengan menuliskan modal usaha, belanja alat dan bahan, belanja kemasan (label dan botol), dan biaya pemasaran. Serta penentuan harga jual yang ditentukan dari harga pokok penjualan serta BEP (break even point) [5].

\section{ULASAN KARYA}

Kegiatan program pengabdian masyarakat dengan pemberdayaan ibu-ibu PKK dusun Boharan dan Patoman desa Keboharan Kecamatan Krian Kabupaten Sidoarjo melalui pengolahan buah kersen (Muntingia calabura L.) menjadi produk sabun dan detergen cair memberikan manfaat yang besar. Para ibu PKK dari kedua dusun sangat bersemangat mengikuti kegiatan ini sebagai bentuk untuk menunjukkan eksistensi dirinya serta sebagai bekal untuk membuka usaha keluarga yang pada akhirnya dapat menambah pemasukan keluarga.

Kendala awal yang dihadapi yaitu keraguan terhadap kemampuan diri dari ibu-ibu PKK untuk membuat sabun dan detergen cair seperti apakah bisa untuk membuat sabun dan detergen, apakah buah kersen bisa dibuat sabun dan detergen, apakah alat dan bahan yang dibutuhkan rumit, bagaimana cara membuat sabun dari buah kersen, apakah bisa menjualnya. Keraguan ini muncul sebagai akibat kurangnya wawasan dan pengetahuan yang dimiliki oleh ibu-ibu PKK tersebut. Namun, dengan kegiatan workshop dan pendampingan tim PPM telah mampu meningkatkan motivasi ibuibu PKK kedua dusun untuk yakin dan berusaha. Upaya perintisan usaha ini selanjutnya dapat dikembangkan dengan sabun dan detergen cair untuk ekstrak yang lainnya seperti ekstrak nanas, jeruk, dll yang tentunya disesuaikan dengan perkembangan pasar.

Kendala selanjutnya yang dihadapi yaitu kendala pemasaran. Hal ini disebabkan karena masih pada tahap awal usaha sehingga pemasaran yang dilakukan masih belum optimal yaitu antara tetangga dan masyarakat sekitar dusun saja. Oleh karena itu hasil keuntungan yang diperoleh masih sedikit. Upaya yang dilakukan yaitu memberi motivasi untuk tidak mudah menyerah dan putus asa dalam mengembangkan usaha yang baru dirintis. Serta dengan memperluas 
pemasaran selanjutnya melalui sosial media yang sudah dibuatkan oleh Tim PPM. Selain itu dapat juga dengan

\section{DAMPAK DAN MANFAAT KEGIATAN}

Dampak dan manfaat kegiatan program pengabdian masyarakat (PPM) ini memberikan wawasan dan pengetahuan sebagai bekal usaha kepada ibu-ibu PKK dusun Boharan dan Patoman Kecamatan Krian Kabupaten Sidoarjo tentang pengolahan dan pemanfaatan buah kersen menjadi suatu barang atau produk yang dapat bernilai ekonomi dalam bentuk sabun mandi, sabun cuci tangan dan detergen cair herbal antibakteri ekstrak buah kersen. Dimana produk yang dihasilkan ini minimal dapat digunakan sendiri sehingga dapat menghemat pengeluaran keluarga serta dapat juga untuk dijual sehingga menambah income yang selanjutnya dapat meningkatkan kesejahteraan keluarga.

\section{KESIMPULAN}

Dari seluruh kegiatan dalam program pelatihan pembuatan sabun herbal pada Ibu-ibu PKK dusun Boharan dan Patoman desa Keboharan kecamatan Krian kabupaten Sidoarjo dapat disimpulkan sebagai berikut:

\section{PENGHARGAAN}

Terima kasih kami ucapkan kepada Universitas Muhammadiyah Sidoarjo, Ketua Lembaga Penelitian Pengabdian dan PemberdayaanMasyarakat, serta mitra ibu-ibu PKK dusun Boharan dan Patoman desa Keboharan kecamatan Krian kabupaten Sidoarjo Jawa Timur. berkoordinasi dengan kegiatan RT/RW atau desa untuk mengenalkan dan melakukan promosi produk.

1. Kegiatan pelatihan yang dilakukan oleh tim PPM-TKP pada mitra membuat motivasi pada masyarakat khususnya desa Keboharan lebih giat belajar untuk menjadi calon pengusaha.

2. Peningkatan pengetahuan masyarakat desa Keboharan tentang kelebihan atau manfaat buah kersen.

3. Pelatihan dan pendampingan pembuatan sabun dan detergen cair herbal antibakteri ekstrak buah kersen, membuat masyarakat mengetahui teknologi pemanfaatan buah kersen, yang sebelumnya diolah secara manual.

4. Meningkatkan pendapatan masyarakat, dengan menjual hasil produk sabun dan detergen cair herbal antibakteri ekstrak buah kersen.

\section{DAFTAR PUSTAKA}

[1] Ami, M.S., Hastuti, U.S., Suarsini, E. 2015. Kajian Daya Antibakteri Ekstrak Etanol Kulit Batang dan Buah Kersen (Muntingia calabura) terhadap Bakteri Escherichia coli dan Staphylococcus aureus secara In Vitro sebagai Bahan Ajar Elektronik pada Matakuliah 
Jurnal Aplikasi Sains dan Teknologi - JAST, Volume 2, Nomor 1, Januari-Juni 2018, e-ISSN 2548-7981

Mikrobiologi. Tesis. Pendidikan Biologi. Universitas Negeri Malang.

[2] Anjani, N.T., Supartono. Mursiti, S. 2016. Sabun Cair Antibakteri dari Ekstrak Buah Kersen (Muntingia calabura L.). Indo. J. Chem. Vol. 5 No. 32016.

[3] Kotler, P. 2001. Manajemen Pemasaran di Indonesia: Analisis, Perencanaan, Implementasi dan
Pengendalian. Salemba Empat. Jakarta.

[4] Maharani, A. 2015. Sabun Cair vs. Sabun Batang Mana yang Terbaik. http://www.sinarharapan.co/news/read /150901278/sabun-cair-vs-sabunbatang-mana-yang-terbaik-. Diakses tanggal 23 Mei 2017 Pukul 14.15.

[5] Stanton, W.J. 2001. Prinsip Pemasaran. Erlangga. Jakarta. 